\title{
Modern and ancient geotherms beneath southern Africa
}

\author{
Sanford Ballard * and Henry N. Pollack \\ Department of Geological Sciences, University of Michigan, Ann Arbor, MI 48109 (U.S.A.)
}

Received September 25, 1987; revised version received December 28, 1987

\begin{abstract}
Estimates of subsurface temperatures in the Archean craton of southern Africa during the Archean derived from diamond thermobarometry studies are remarkably similar to temperatures estimated for the same depths today, even though heat production in the earth and the mean global heat flow were probably substantially higher in the Archean. We present multi-dimensional numerical models for the thermal environment of the Archean craton in southern Africa during the Archean in which deep mantle heat is diverted away from the craton toward the surrounding oceanic lithosphere by a lithospheric root beneath the craton. Extrapolation of present-day models to thermal conditions appropriate for the Archean is inadequate to explain the similarity of present-day and Archean temperatures in the cratonic root. Reconciliation of the modern and ancient temperature estimates requires either relaxation of the constraints that the cratonic crustal heat production and/or the earth's mean mantle temperature were higher in the Archean than they are today, or that substantial "erosion" of the lithosphere comprising the cratonic root has occurred since the Archean. The latter possibility could perhaps result from revolatilization of the cratonic root in association with thermal perturbations in the mantle, for which there is evidence in southern Africa in the form of post-Archean tectonic and igneous activity.
\end{abstract}

\section{Introduction}

An apparent paradox has developed in recent years concerning the early thermal regime of the stabilized Archean cratons. On the one hand, several lines of evidence indicate that Archean temperatures, both in the crust and cratonic upper mantle, were not very different from those of the present day. On the other hand, the total heat loss from the Earth must have been substantially higher in the Archean than at present because the heat production in the Earth was probably 2-3 times the present-day rate. It has frequently been suggested [1-3] that these two apparently contradictory observations can perhaps be reconciled if the extra heat generated in the Archean was lost not through the cratons where relatively low Archean temperatures are recorded, but through the surrounding Archean oceans which have long since been recycled back into the mantle. Implicit in this reconciliation is the existence of horizontal as well as vertical components of heat transfer, and a

\footnotetext{
* Presently at: Sandia National Laboratories, Geophysics Division-6231, Albuquerque, NM 87185, U.S.A.
}

three-dimensional, rather than one-dimensional temperature field.

In a series of papers setting forth a model of the process of cratonic stabilization, Jordan [4-6] envisioned a mantle root zone from which the overlying cratonic crust was derived. He proposed that the process of crustal extraction involved selected major element and LIL depletion of the mantle beneath the craton which left it less dense than the surrounding mantle. That the depleted root would be more refractory and rheologically distinct from the surrounding mantle was suggested by Jordan [7] and Davies [2]. These themes were developed more fully by Pollack [8] with special emphasis on the depletion of volatiles and the resultant stiffening of the root zone, effectively removing it from mantle convection and relegating it to a conductive thermal regime. Undepleted upper mantle adjacent to the root would remain less viscous and permit convection to reach higher levels than beneath the conductive cratonic root. Because convection is the more efficient heat transfer mechanism, some mantle heat would be diverted away from the cratonic root and delivered to the surface through non-cratonic ter- 
rains. The diversion of heat would likely have had a significant effect on temperatures in and around the cratonic root throughout its history.

In a recent paper [9] we suggested, in part on the basis of heat flow observations, that such a lithospheric root exists today beneath the Archean craton in southern Africa, and diverts deep mantle heat toward the younger surrounding mobile belts. If this diversion mechanism was sufficiently active in the Archean, the extra heat generated at that time might also have been diverted away from the craton, keeping the heat flow into the base of the cratonic root low enough so that the thermal conditions within the cratonic root in the Archean might have been similar to what they are today. In the present paper we investigate the Archean thermal structure beneath southern Africa with a model which is conceptually similar to our present-day model set forth in [9], and which provides insights into factors controlling the thermal structure of cratons in the Archean.

\section{Temperature estimates for Archean cratons dur- ing the Archean}

Before exploring the thermal models, we review briefly the evidence for relatively cool cratons during the Archean. Burke and Kidd [1] suggested that if the temperature at the base of the crust in the Superior Province of Canada during the Archean had exceeded the present-day temperatures at those depths by more than about $30 \%$, partial melting would have occurred resulting in the exposure of minimum melting granites at the surface today. That such granites are not observed in the region implies that deep crustal temperatures in the Archean did not exceed those that exist there today by more than a few hundred degrees.

England and Bickle [10] noted that granulites that equilibrated at pressures of 9-10 kbar are exposed at the surface of Archean terrains, implying the existence of mountain ranges in the Archean with elevations comparable to those in Tibet today. England and Bickle also point out that the elevations that can be achieved by mountain ranges are very sensitive to the temperatures in the lithosphere because of the temperature dependence of plastic deformation. If there were mountain ranges in the Archean with elevations comparable to the elevations of present-day mountains then the lithospheric geothermal gradients at that time could not have greatly exceeded those of the present-day.

The most relevant estimates of thermal conditions within the Archean cratons during the Archean come from thermobarometry studies of silicate inclusions in diamonds found in kimberlite pipes located in the Kaapvaal Craton [11,12]. These inclusions formed at temperatures and depths of $900-1200^{\circ} \mathrm{C}$ and $150-200 \mathrm{~km}$, respectively. $\mathrm{Sm} / \mathrm{Nd}$ model ages [13] from similar inclusions in diamonds from the same locations suggest that the inclusions date from about $3.2 \mathrm{Ga}$ and by inference that the diamonds must also have formed at that time. Thus, the temperature and depth recorded by the inclusions reflect the conditions within the lithosphere of the Kaapvaal Craton at the time of diamond genesis, $3.2 \mathrm{Ga}$ ago [12].

These results are particularly significant for two reasons. First, the isotopic model ages suggest that the Kaapvaal Craton had stabilized to a depth of at least $150-200 \mathrm{~km}$ by $3.2 \mathrm{Ga}$ ago, only about $300 \mathrm{Ma}$ after the principal Archean magmatic episodes of the region. Second, the thermobarometry data suggest that the temperatures in the Archean at depths of $150-200 \mathrm{~km}$ were virtually the same as the present-day temperatures estimated for the same depths. While the studies of Burke and Kidd [1] and England and Bickle [10] mentioned above place upper limits on the temperatures and temperature gradients in the Archean cratons early in their history, they would still allow the cratonic root to have been a few hundred degrees warmer in the Archean than in the present-day. The constraint that temperatures at substantial depths within the cratonic lithosphere are virtually unchanged since the Archean is much more stringent.

Davies [2] examined the apparent contradiction between high heat production and low cratonic temperature gradients in the Archean. He observed that the temperature drop in the present-day across oceanic and Archean-age continental lithosphere is roughly the same even though the latter is considerably thicker, implying steeper temperature gradients in the oceanic lithosphere relative to the continental lithosphere. He suggested that in the Archean, when the heat flow and heat production were higher than at present, the oceanic litho- 
sphere, which is the upper thermal boundary layer of the convecting mantle, would have been about half its present thickness while the Archean cratons, chemically distinct and isolated from the convecting mantle, would have a constant thickness through time. This would mean that in the Archean, most of the extra heat loss from the Earth would have occured through the oceans while temperatures in the continental crust and lithosphere would have increased by only about $150^{\circ} \mathrm{C}$.

Our models are similar to those of Davies [2] in that we also consider the roots beneath the Archean cratons to be chemically and rheologically distinct from the surrounding mantle. However, our models differ in important respects. Davies considers separate one-dimensional models for cratonic and surrounding terrains, whereas we couple the two into a single model. We favor this approach because if focuses on the mechanism which creates and maintains the difference in thermal structure between the two terrains. Moreover, the temperatures in and around cratonic roots in multi-dimensional models are significantly different from those in one-dimensional models, underscoring the importance of the multi-dimensional analysis.

\section{Present-day thermal structure of the lithosphere in southern Africa}

The Archean nucleus of the southern African subcontinent is the Kaapvaal-Limpopo-Zimbabwe Craton which is surrounded by a number of Proterozoic and younger mobile belts that experienced tectonothermal events of different character at widely different post-Archean times. The 84 terrestrial heat flow measurements from the region reveal a substantial contrast in surface heat flow of about $25 \mathrm{~mW} \mathrm{~m} \mathrm{~m}^{-2}$ between the center of the Archean craton where the surface heat flow is about $40 \mathrm{~mW} \mathrm{~m}^{-2}$ and the surrounding mobile belts where it is about $65 \mathrm{~mW} \mathrm{~m}^{-2}$ [14]. In [9] we suggested that this present-day contrast in surface heat flow may derive from two causes: (1) a shallow geochemical contribution arising from a contrast in crustal heat production between the Archean and younger terrains, and (2) a deeper, geodynamical contribution arising from the diversion of deep mantle heat by a cratonic root be- neath the Kaapvaal-Limpopo-Zimbabwe Craton. The models were constrained by the observed pattern of surface heat flow, estimates of the mean heat production in continental crust, estimates of the contrast in crustal heat production between Archean and younger terrains, and by thermobarometry data from xenoliths brought to the surface in Cretaceous kimberlites in southern Africa [11]. Because of the relatively short interval from the Cretaceous to the present, these Cretaceous conditions are considered useful estimates for the present-day as well.

Two characteristic models, designated P1 and P2, that satisfy all the present-day constraints outlined in [9] and that are representative of the full range of satisfactory present-day models are illustrated in Figs. $1 a-c$ and $2 a-c$, respectively. The surface heat flow that results from each of these models is shown in Figs. 1a and 2a. In model P1 there is no contrast in crustal heat production between the craton and younger surrounding terrains, and all of the contrast in surface heat flow results from the diversion of heat by a lithospheric root extending to $400 \mathrm{~km}$ depth beneath the craton. In Model P2 the contrast in surface heat flow derives approximately equally from a contrast in crustal heat production between the two terrains and from the diversion of deep mantle heat by a lithospheric root that extends to $220 \mathrm{~km}$ depth beneath the craton.

The subsurface temperature fields resulting from the two models are illustrated in Figs. 1b and $2 \mathrm{~b}$. The upward bowing of the isotherms in the sublithospheric mantle below the cratonic roots results from the diversion of deep mantle heat away from the craton toward the surrounding mobile belts. The more pronounced warping of the sublithospheric isotherms in model $P 1$ relative to $\mathrm{P} 2$ is a reflection of the fact that the thicker craton in P1 diverts more heat than the thinner craton in model $\mathrm{P} 2$.

Two geotherms from each of the present-day models are shown in Figs. 1c and 2c; in each case, one geotherm comes from the center of the craton and the other from the mobile belts at the periphery of the model far from the craton. Down to a depth near the base of the root the temperature in the craton is lower than at the same depth beneath the mobile belts. Near the base of the root the temperatures within and adjacent to the root be- 
a)

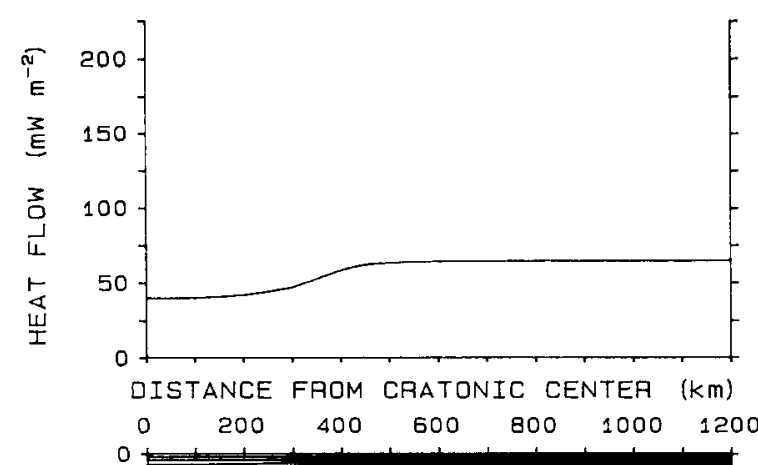

b)
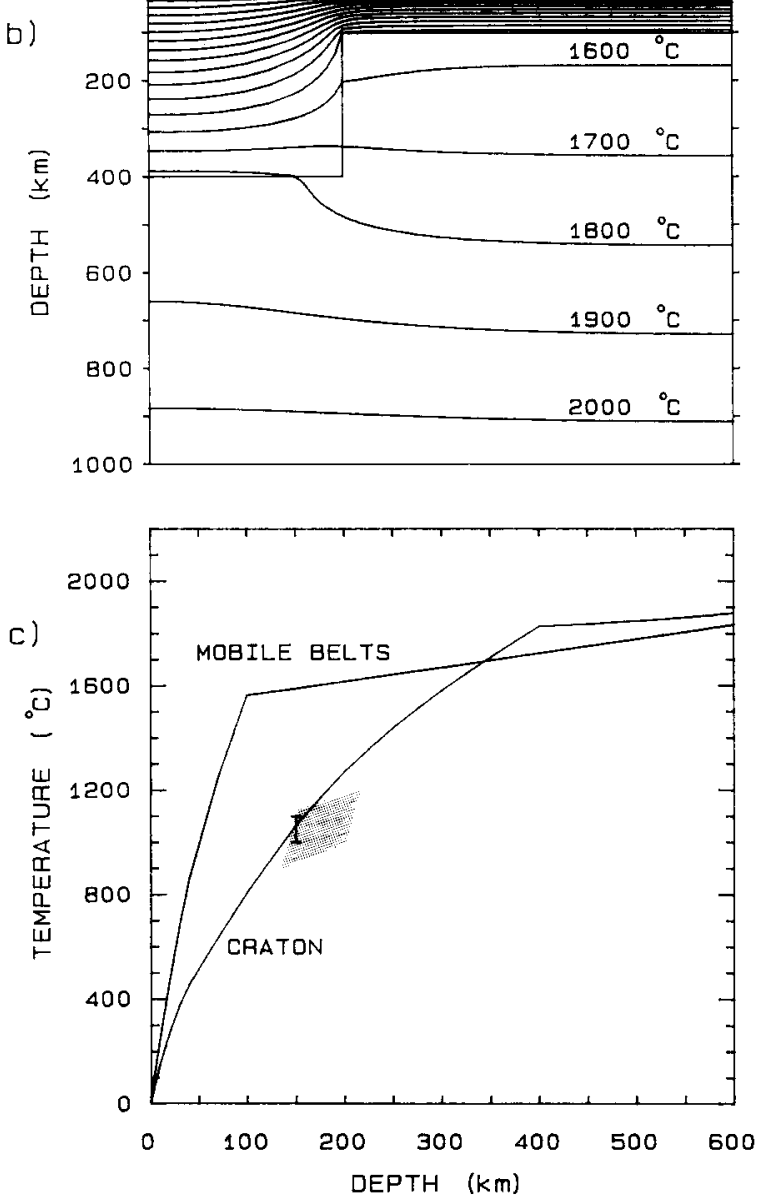

d)

ARCHEAN

(A1)

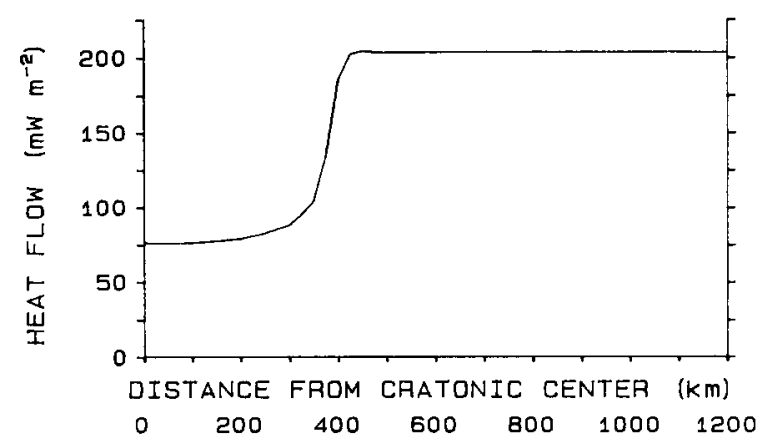

e)

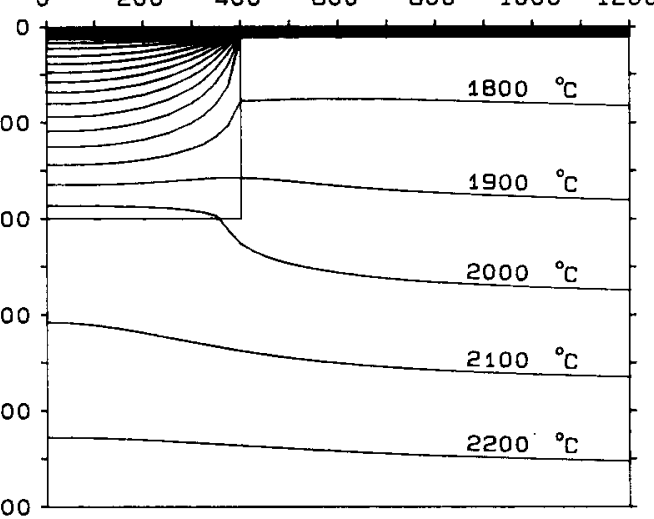

f)

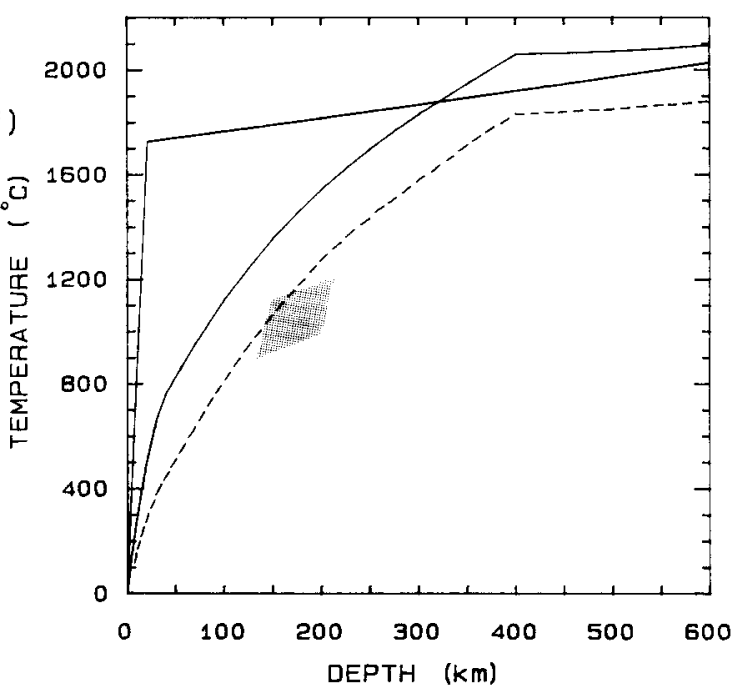

Fig. 1. Models P1 and Al of the thermal structure of the lithosphere in southern Africa in the present day (a-c) and in the Archean $(\mathrm{d}-\mathrm{f})$. All the contrast in surface heat flow between the craton and surrounding mobile belts in the present-day model results from the diversion of heat by the cratonic root; there is no contrast in crustal heat production between the two terrains. Surface heat flow and subsurface temperatures predicted by the models are shown in (a, d) and (b, e), respectively. Solid curves in (c, $f$ ) are geotherms, one from the center of the craton and the other from the periphery of the model, far from the craton. Dashed curve in (f) reproduces for comparison the geotherm from the center of the craton in the present-day model shown in (c). Shaded region represents the thermal conditions within the cratonic root during the Archean suggested by the diamond thermobarometry data [12]. Vertical bar in (c) is the temperature constraint derived from xenolith thermobarometry data [11]. 

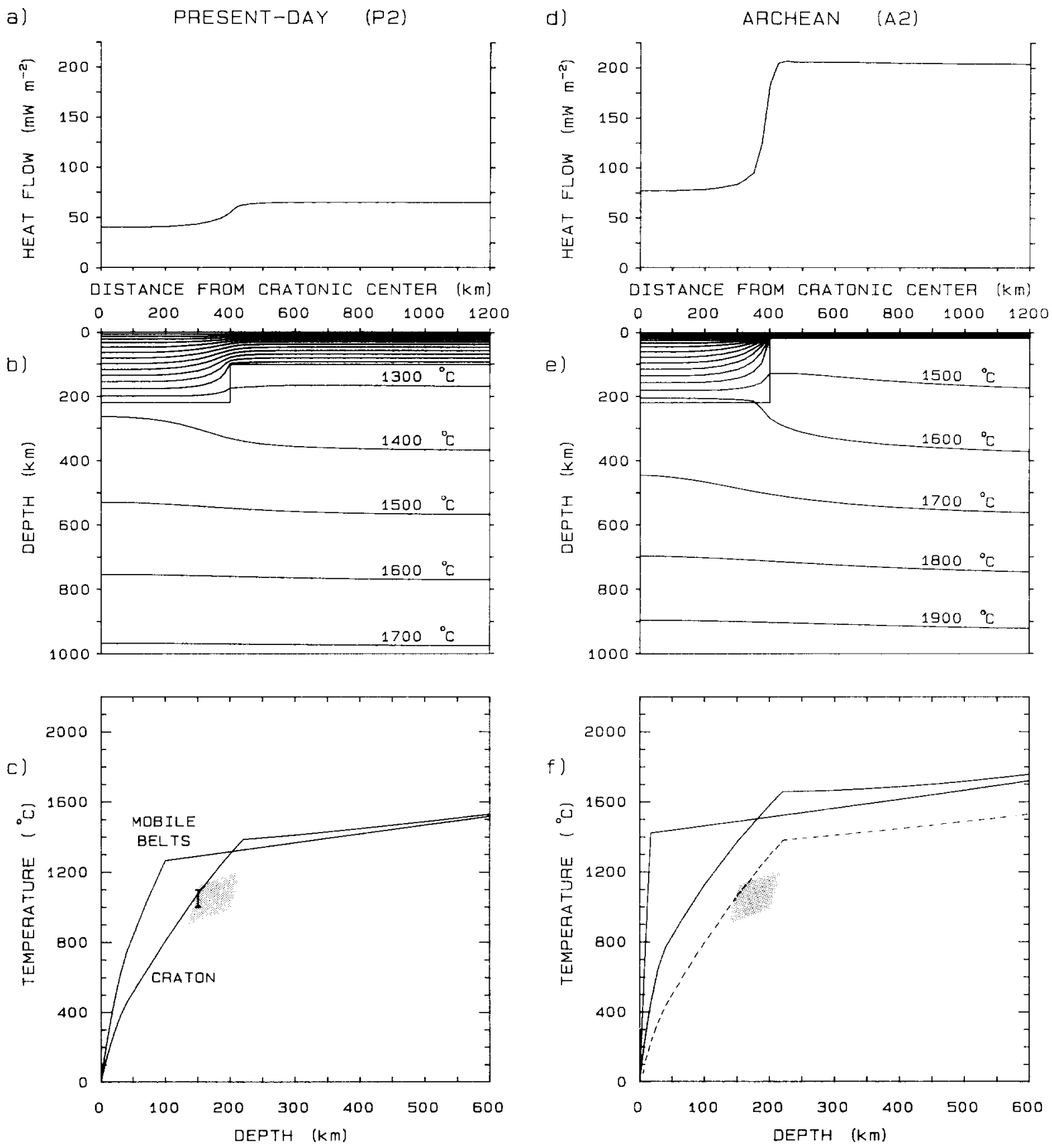

Fig. 2. Models P2 and A2 of the thermal structure of the lithosphere in southern Africa in the present day (a-c) and the Archean $(d-f)$. The contrast in surface heat flow between the craton and surrounding mobile belts in the present-day model derives approximately equally from the diversion of heat by the cratonic root and from a contrast in crustal heat production between the two terrains. Surface heat flow and subsurface temperatures predicted by the models are shown in (a, d) and (b, e), respectively. Solid curves in ( $c, f)$ are geotherms, one from the center of the craton and the other from the periphery of the model, far from the craton. Dashed curve in (f) reproduces for comparison the geotherm from the center of the craton in the present-day model shown in (c). Shaded region represents the thermal conditions within the cratonic root during the Archean suggested by the diamond thermobarometry data [12]. Vertical bar in (c) is the temperature constraint derived from xenolith thermobarometry data [11]. 
come the same. This is reflected by the intersection of the cratonic and mobile belt geotherms in Figs. $1 \mathrm{c}$ and $2 \mathrm{c}$ and by approximately horizontal isotherms in Figs. $1 \mathrm{~b}$ and $2 \mathrm{~b}$. At and below the base of the root the temperature is actually warmer than that of the surrounding mantle. The existence of higher temperatures at the base of the root compared to the adjacent mantle is characteristic of the diversion mechanism and appears in all models in which diversion plays a role.

The vertical bars in Figs. $1 \mathrm{c}$ and $2 \mathrm{c}$ represent the temperature constraint on present-day models imposed by thermobarometry studies of xenoliths brought to the surface in Cretaceous kimberlite pipes in southern Africa [11]. The shaded regions illustrate the range of temperatures and depths of formation of the Archean diamonds reported by Boyd et al. [12] and represent conditions within the cratonic root during the Archean. The similarity of these thermal conditions indicates that the temperatures at depths of $150-200 \mathrm{~km}$ beneath the craton were virtually the same in the Archean as they are today. The cratonic geotherms of both present-day models shown in Figs. 1 and 2 pass through the range of Archean conditions derived from the diamond thermobarometry data.

\section{Thermal structure of the lithosphere in southern Africa in the Archean}

We now turn to models for the thermal structure of southern Africa in the Archean, asking the question whether or not enhanced diversion during the Archean can compensate for the higher heat production and heat flow at that time, and yield temperatures in the root consistent with the diamond thermobarometry data. There are three fundamental differences between the thermal environment of the Archean craton of southern Africa $3.2 \mathrm{Ga}$ ago compared to the present. First, the post-Archean continental mobile belts which surround the craton today had not yet formed in the Archean, so the craton was probably surrounded by an Archean ocean. The highly mobile oceanic lithosphere, then as in the present-day, would have been the principal vehicle of heat loss, with heat preferentially avoiding the high thermal resistance of the craton. Second, heat production and heat flow out of the Earth during the Archean were probably 2-3 times higher than at present because of the half-lives of the radioelements that give rise to the heat production. However, not all of the augmented heat production was deep-seated and therefore available for diversion. Some was resident in the thenrecently stabilized crust of the Archean continental nuclei, generating heat also at 2-3 times the present-day rate. Third, the potential temperature of the mantle (defined as the horizontal averaged temperature of the mantle beneath the non-cratonic lithosphere extrapolated to the surface along an adiabatic gradient) was probably a few hundred degrees warmer in the Archean than it is today as suggested by parameterized convection models [15] and perhaps by the highly magnesian komatiite lavas of the Archean.

Useful starting models for exploration of the Archean thermal regime are the characteristic present-day models, $\mathrm{P} 1$ and $\mathrm{P} 2$, but incorporating the recognized differences between the Archean and the present-day discussed above. Model A1 in Fig. 1d-f and model A2 in Fig. 2d-f correspond to models $\mathrm{P} 1$ and $\mathrm{P} 2$ in Figs. $1 \mathrm{a}-\mathrm{c}$ and $2 \mathrm{a}-\mathrm{c}$, respectively. The cratons have the same dimensions as they do in the corresponding present-day models but the heat production in the cratonic crust and subcrustal lithosphere is 2.5 times its value in the corresponding present-day model. The areally weighted average surface heat flow out of the Archean models is $200 \mathrm{~mW} \mathrm{~m}^{-2}$, which is 2.5 times the present-day mean global surface heat flow. The thickness of the oceanic lithosphere surrounding the craton in the Archean models is adjusted to yield temperatures in the convecting mantle beneath the oceanic lithosphere $200^{\circ} \mathrm{C}$ warmer than those beneath the mobile belts in the corresponding present-day model.

More heat is diverted away from the craton in the Archean models than in the present-day models, lending credence to the hypothesis [1-3] that much of the additional heat generated in the Earth in the Archean may have been lost through the oceans. The contrast in surface heat flow between the craton and the surrounding terrain in the Archean models, illustrated in Figs. 1d and 2d, is about $125 \mathrm{~mW} \mathrm{~m}^{-2}$ compared to only $25 \mathrm{~mW}$ $\mathrm{m}^{-2}$ in the present-day models shown in Figs. 1a and $2 \mathrm{a}$. Two geotherms from each of the Archean models are illustrated by solid curves in Figs. If and $2 \mathrm{f}$; in each case, one represents the center of 
the craton and the other an oceanic geotherm from the boundary of the model, far from the craton. The geotherms illustrated with dashed curves represent the temperatures in the craton from the corresponding present-day models. The similarity of the temperature gradients in the cratonic subcrustal lithosphere in the present-day and Archean models suggests similar present-day and Archean heat flow in that depth range despite the significantly higher average surface heat flow out of the Archean models, another indication that the craton diverts much more heat in the Archean models than it does in the present-day models. The higher surface heat flow from the craton in the Archean models relative to the present-day models is the result of higher Archean heat production within the cratonic crust.

These models for the thermal conditions in and around the craton during the Archean do not, however, satisfy the diamond thermobarometry results [12], represented by the shaded regions in Figs. 1f and $2 f$. There are two reasons for this. The first is that the higher crustal heat production in the Archean models results in temperatures at the base of the cratonic crust being about $300^{\circ} \mathrm{C}$ warmer than in the corresponding present-day models. The second is that the mantle is some $200^{\circ} \mathrm{C}$ warmer in the Archean models resulting in temperatures at the base of the cratonic root about $200^{\circ} \mathrm{C}$ warmer relative to the present-day models. Given a higher temperature at the base of the crust because of higher crustal heat production and higher temperatures at the base of the root because of higher mantle temperatures, it would be impossible for the temperatures at intermediate depths to have been the same in the Archean as they are today. Even though much more heat is diverted in the Archean models than is diverted in the corresponding present-day models, the Archean models as posed do not satisfy the diamond thermobarometry data.

A resolution to this problem might be that the diamond thermobarometry data in fact may represent much younger thermal conditions in the cratonic root, implying re-equilibration of the major element geochemistry upon which the thermobarometry is based at some time in more recent earth history. However, the Sm-Nd model ages [13] indicate an Archean age for the inclusions, and thus one would need to invoke a mechanism for major element transport and re-equilibration while trace element concentrations remained unaffected. Such a selective re-equilibration scenario seems unlikely. A second possible resolution would be if the diamonds formed in ancient subducted oceanic lithosphere which later accreted to the base of the craton [16, 17 and references therein]. In this scenario the age and thermobarometry of the inclusions may be valid, but irrelevant as evidence of conditions within the cratonic root during the Archean.

Assuming, however, that the diamond data are a relevant Archean constraint on temperatures within the cratonic root, what modifications then can be made to the Archean models to make them consistent with the diamond thermobarometry? One is to relax the constraint that the potential temperature of the mantle was warmer in the Archean than it is today. Then the temperatures near the base of the root in the Archean models could be lower than they are in models A1 and $\mathrm{A} 2$, reducing the temperatures throughout the cratonic root. In order to satisfy the diamond thermobarometry data, however, the mantle potential temperature would have to be about $400^{\circ} \mathrm{C}$ cooler than in the Archean models shown in Figs. 1d-f and 2d-f, implying that the mantle would have warmed some $200^{\circ} \mathrm{C}$ since the formation of the diamonds in the Archean. While the amount of cooling the mantle has experienced since the Archean may not be well agreed upon, a warming of the mantle since the Archean runs counter to the conventional wisdom concerning the thermal evolution of the earth.

Another change to the Archean models which would reduce temperatures in the root is to have the crustal heat production in the Archean models be lower than in the corresponding present-day models. This would result in temperatures at the base of the crust being cooler in the Archean models, which, when coupled with higher temperatures near the base of the root caused by higher mantle potential temperatures, might result in the temperatures at the depths where the diamonds formed being approximately the same in the Archean as in the present-day. This scenario would require substantial enrichment of the cratonic crust in heat-producing radioisotopes sometime during its later history. However, the KaapvaalLimpopo-Zimbabwe Craton in southern Africa 
shows no evidence of widespread post-Archean crustal genesis or remobilization, and thus such an enrichment would seem unlikely.

Another modification to the models which would result in the diversion of more heat while still allowing both high cratonic crustal heat production and mantle potential temperature in the Archean, would be to allow the cratonic root to have been larger, both horizontally and vertically, at the time of formation of the diamonds than it is today. In the Archean models shown in Figs. 1d-f and $2 \mathrm{~d}-\mathrm{f}$ the subsurface temperatures at the center of the craton are significantly affected by lateral heat transfer from the warmer mantle surrounding the cratonic root. Increasing the radius of the cratonic root removes this heat source to greater distances, reducing the temperatures at the depth of the diamonds near the center of the craton. If the cratonic lithosphere were also thicker in the Archean than it is today, implying the root has thinned with time, then the conductive cratonic geotherm would have extended to greater depths in the Archean compared to the present day, resulting in the diversion of even more heat away from the cratonic root in the Archean.

The model sensitivity experiments reported in [9] suggest that changes in thickness of a relatively thin cratonic root have a larger effect on the diversion mechanism than do similar thickness changes to a relatively thick root. To divert enough additional heat in the Archean to satisfy the diamond thermobarometry data and end up with a relatively thick root today, as in model $\mathrm{P} 1$, requires a very thick root in the Archean and a large reduction in root thickness with time. To end up with a relatively thin root in the present day, as in model P2, requires a cratonic root of more modest thickness in the Archean and less reduction in root thickness between the Archean and the present day in order to achieve a sufficient reduction in diverted heat with time. These relationships favor a root beneath southern Africa today similar to that in model P2.

To illustrate the effects of allowing the size of the cratonic root to shrink with time, we present in Fig. 3d-f another model for the Archean, model A2', which is similar to model A2 in Fig. 2d-f but with the radius and thickness of the craton set at 600 and $500 \mathrm{~km}$, respectively, as compared to 400 and $220 \mathrm{~km}$ in model $\mathrm{A} 2$. The larger radius of the craton protects its interior from heat transferred horizontally into it from the sublithospheric mantle surrounding it, and the thicker cratonic lithosphere diverts more heat away from the craton toward the surrounding ocean. The effect of these changes is that the temperature in the cratonic root at the depth where the diamonds formed is reduced relative to the model A2. Two cratonic geotherms, one from model $\mathrm{A}^{\prime}$ and one from model P2, are compared in Fig. 3f. This pair of models satisfies the constraints imposed by greater heat flow and heat production and higher potential temperture of the mantle in the Archean and, most significantly, the temperatures at a depth of $150-200 \mathrm{~km}$ are the same in the two models, as required by the diamond thermobarometry data.

The suggestion that the craton may have been larger in the Archean than it is today implies that "erosion" of the cratonic root occurred at some time during its history. Is it reasonable to suggest that a craton has been subjected to such a process? Because low temperatures and volatile depletion are two likely factors that isolate the cratonic root from mantle convection, then higher temperatures and revolatilization may be key ingredients in the remobilization of the root into the convective regime. The eruption of the Ventersdorp lavas in the late Archean, the intrusion of the Bushveld Complex and similar ultramafic intrusions in the Proterozoic, the eruption of Karoo basalts during the breakup of Gondwana in the Mesozoic, kimberlite penetration during the Cretaceous, metasomatized xenoliths and several episodes of mobile belt accretion in post-Archean times all indicate that the Archean cratonic lithosphere has been subjected to significant thermal perturbations and volatile fluxes several times in its long history. Such processes could result in a significant decrease in the viscosity of the base of the cratonic root and cause it to become reincorporated into the mantle circulation.

There are buoyancy and freeboard issues associated with root erosion that also must be considered. The existence of primary sedimentary structures and pillowed lavas in the Archean rocks of the southern African craton indicates these rocks have probably never been very far from sea level since their formation. Yet the erosion of the cratonic root would remove depleted lower density lithosphere and replace it with undepleted cir- 
a)

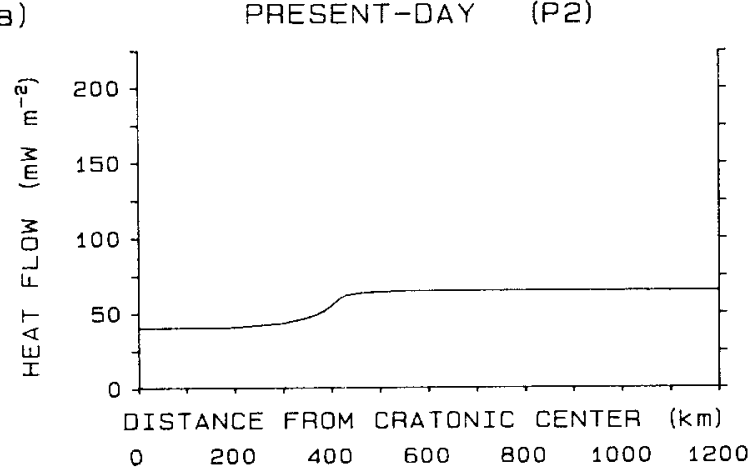

b)

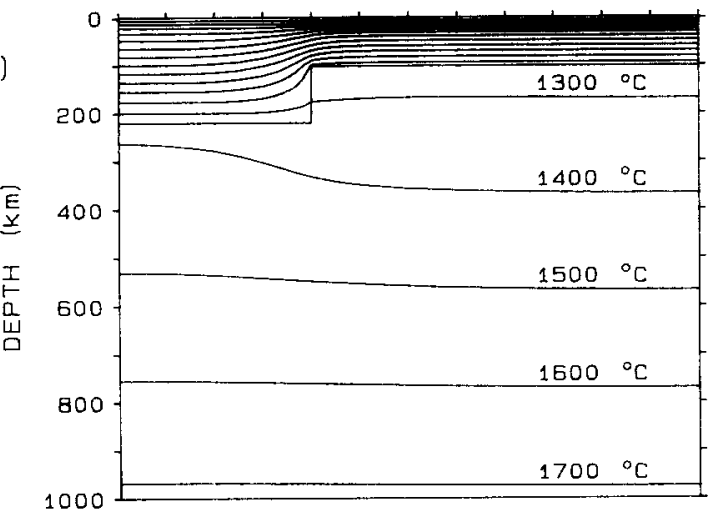

c)

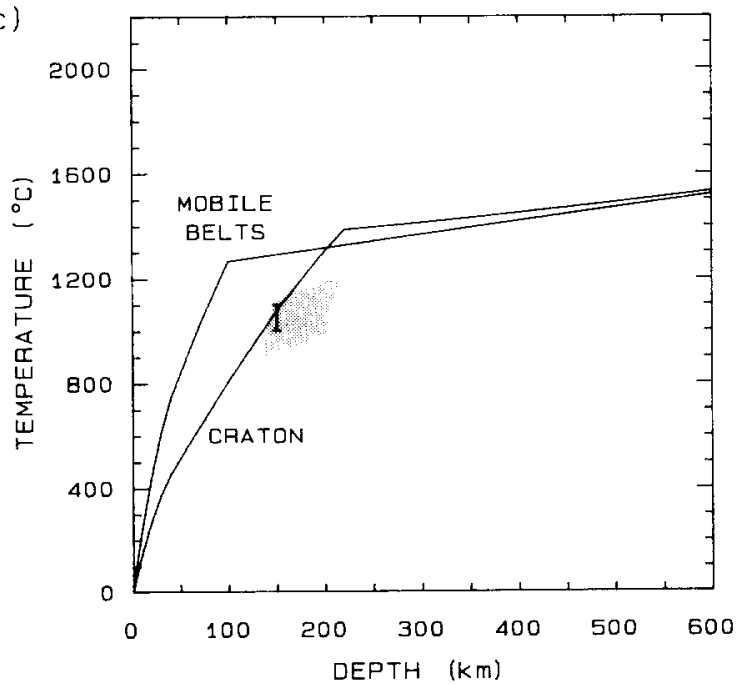

d) ARCHEAN (A2')

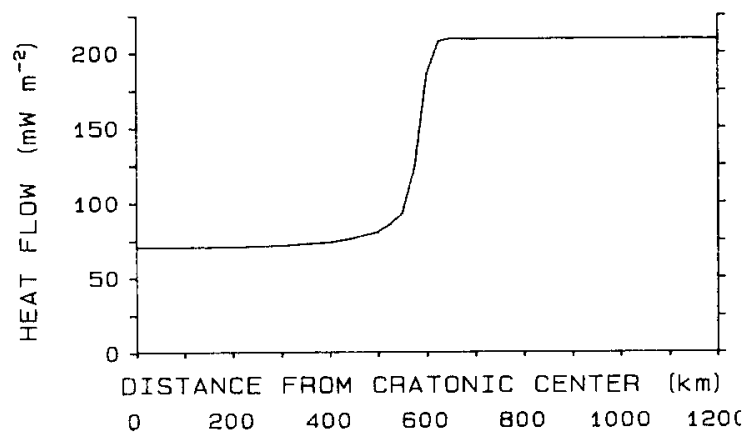

e)

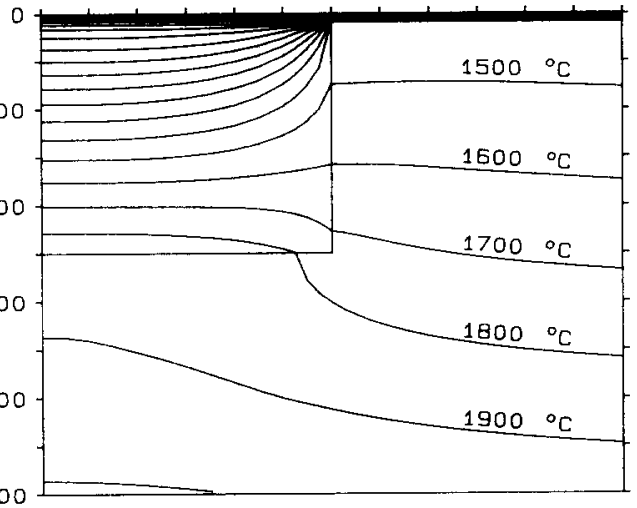

f)

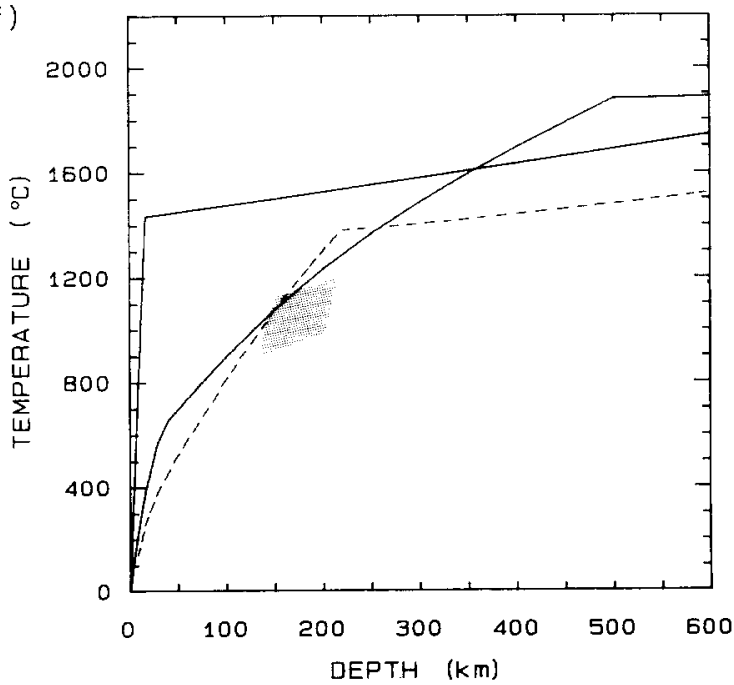

Fig. 3. Models P2 and A2' of the thermal structure of the lithosphere in southern Africa in the present day (a-c) and in the Archean $(d-f)$. The present-day model is the same as appears in Fig. 2a-c. The larger radius and thickness of the cratonic root in the Archean model imply "erosion" of the root since that time. Surface heat flow and subsurface temperatures predicted by the models are shown in (a, d) and (b,e), respectively. Solid curves in (c, $f)$ are geotherms, one from the center of the craton and the other from the periphery of the model, far from the craton. Dashed curve in (f) reproduces for comparison the geotherm from the center of the craton in the present-day model shown in (c). Shaded region represents the thermal conditions within the cratonic root during the Archean suggested by the diamond thermobarometry data [12]. Vertical bar in (c) is the temperature constraint derived from xenolith thermobarometry data [11]. 
culating mantle. Can the diminished remainder of the craton avoid significant vertical isostatic movement under such circumstances? The answer must be sought in a comparison of the relative buoyancy between the craton and its surroundings both in the Archean and in the present day. If the eroded craton is no more or less buoyant relative to the surrounding mantle in the present day than the larger craton was in the Archean, then there is no reason for substantial uplift or subsidence of the cratonic surface. Our preliminary calculations show such a scenario to be entirely feasible: the eroded cratonic root is replaced by undepleted higher density mantle, but the surrounding mantle also becomes more dense from cooling by a few hundred degrees. When the effects due to addition of the mobile belts and lateral temperature variations in the sub-cratonic mantle are included, a zero net change in cratonic buoyancy can be achieved, if the average cratonic density reduction due to depletion is about $0.015-0.020 \mathrm{~g} \mathrm{~cm}^{-3}$, a change not unlike that calculated by Jordan [7] from mineralogical arguments.

\section{Summary}

The apparently contradictory observations that the heat flow and heat production in the Earth were probably substantially higher in the Archean than they are today but temperatures in the cratonic lithosphere were not, can be reconciled if the extra heat produced deep within the Earth in the Archean was diverted away from the cratons by lithospheric roots beneath the cratons and lost through the oceanic lithosphere which presumably surrounded the cratonic nuclei in the Archean.

Initial models for the thermal structure of the lithosphere in southern Africa during the Archean, in which the dimensions of the cratonic root are the same as in characteristic present-day models, satisfy two criteria concerning the thermal environment of the craton during the Archean: (1) the global heat flow and the cratonic crustal heat production were both 2.5 times greater in the Archean than today, and (2) the potential temperature of the mantle was $200^{\circ} \mathrm{C}$ warmer than it is at present. Such models do not, however, satisfy the diamond thermobarometry data of Boyd et al. [12] which indicate that the temperatures in the depth range of $150-200 \mathrm{~km}$ in the cratonic root in southern Africa were the same in the Archean as they are today. To satisfy the two criteria above as well as the diamond thermobarometry data, we suggest that the craton may have been larger in the Archean than it is today, in both its horizontal and vertical dimensions. The larger radius of the craton in the past would have protected the interior of the root from heat transferred into it horizontally from the mantle beneath the surrounding oceanic lithosphere. and the greater cratonic thickness in the Archean would have extended the conductive cratonic geotherm to greater depths, resulting in the diversion of more deep mantle heat away from the craton, further reducing temperatures within it.

A larger cratonic root in the past implies that erosion of the root has occurred during its long history. There is evidence, in the form of postArchean igneous activity and peripheral mobile belt accretion, that the craton has been subjected to significant thermal perturbations at various times in the past. These events may have introduced extra heat and/or volatiles into the cratonic lithosphere, rendering it more susceptible to entrainment in mantle convection and hence removing portions of it from the conductive lithosphere.

Our primary conclusion in this paper is that it is difficult to find a simple resolution to the apparent contradiction between the similarity of modern and ancient temperatures in the cratonic lithosphere and greater heat production and heat flow in the Archean. Satisfactory models for the present-day thermal setting of southern Africa, when extrapolated to conditions appropriate for the Archean, do not satisfy the Archean diamond thermobarometry data. Our models suggest that a reduction in the size of the cratonic root subsequent to the formation of the diamonds in the Archean is one mechanism which can yield thermal conditions consistent with both Archean and present-day constraints. Other possible pathways away from the dilemma might include relaxation of assumptions about the Archean thermal environment, such as greater cratonic crustal heat production, higher mantle temperatures, or that the diamond thermobarometry is truly representative of the Archean environment and not a reequilibration to present-day conditions. All of these alternatives would require a re-evaluation of certain strongly held views, and are no less 
dramatic solutions than the cratonic "erosion" which we have suggested.

\section{Acknowledgements}

This research was supported by the U.S. National Science Foundation, grants EAR-8319394 and EAR-8706599. The work performed at Sandia National Laboratories is supported by the U.S. Department of Energy under contract number DE-AC04-76DP00789 for the Office of Basic Energy Sciences. We thank Kevin Furlong and F.R. Boyd for constructive reviews.

\section{References}

1 K. Burke and W.S.F. Kidd, Were Archean continental geothermal gradients much steeper than those of today?, Nature 272, 240-241, 1978.

2 G.F. Davies, Thickness and thermal history of continental crust and root zones, Earth Planet. Sci. Lett. 44, 231-238, 1979.

3 M.J. Bickle, Heat loss from the Earth: a constraint on Archean tectonics from the relation between geothermal gradients and the rate of plate production, Earth Planet. Sci. Lett. 40, 301-315, 1978.

4 T.H. Jordan, The continental tectosphere, Rev. Geophys. Space Phys. 13, 1-12, 1975.

5 T.H. Jordan, Composition and development of the continental tectosphere, Nature 274, 544-548, 1978.

6 T.H. Jordan, Continents as a chemical boundary layer,
Philos. Trans. R. Soc. London, Ser. A 301, 359-373, 1981.

7 T.H. Jordan, Mineralogies, densities and seismic velocities of garnet lherzolites and their geophysical implications, in: The Mantle Sample: Inclusions in Kimberlites and Other Volcanics, F.R. Boyd and H.O.A. Meyer, eds., pp. 1-14, American Geophysical Union, Washington, D.C., 1979.

8 H.N. Pollack, Cratonization and thermal evolution of the mantle, Earth Planet. Sci. Lett. 80, 175-182, 1986.

9 S. Ballard and H.N. Pollack, Diversion of heat by Archean cratons: a model for southern Africa, Earth Planet. Sci. Lett. 85, 253-264, 1987.

10 P. England and M. Bickle, Continental thermal and tectonic regimes during the Archean, J. Geol. 92, 353-367, 1984.

11 F.R. Boyd and J.J. Gurney, Diamonds and the African lithosphere, Science 232, 472-477, 1986.

12 F.R. Boyd, J.J. Gurney and S.H Richardson, Evidence for a $150-200 \mathrm{~km}$ thick Archean lithosphere from diamond inclusion thermobarometry, Nature 315, 387-389, 1985.

13 S.H. Richardson, J.J. Gurney, A.J. Erlank and J.W. Harris, Origin of diamonds in old enriched mantle, Nature 310 , 198-202, 1984

14 S. Ballard, H.N. Pollack and N.J. Skinner, Terrestrial heat flow in Botswana and Namibia, J. Geophys. Res. 92, 6291-6300, 1987.

15 G. Schubert, D. Stevenson and P. Cassen, Whole planet cooling and the radiogenic heat source contents of the earth and moon, J. Geophys. Res. 85, 2531-2538, 1980.

16 D.J. Schulze, Calcium anomalies in the mantle and a subducted metaserpentinite origin for diamonds, Nature 319 , 483-485, 1986.

17 I.D. MacGregor and W.I. Manton, Roberts Victor eclogites: ancient oceanic crust, J. Geophys. Res. 91, 14063-14079, 1986. 